\title{
Common peroneal nerve palsy: a clinical and electrophysiological review
}

\author{
H. BERRY ${ }^{1}$ AND P. M. RICHARDSON
}

From the Division of Neurology, St. Michael's Hospital, University of Toronto, Ontario, Canada

SYNOPSIS In a series of 70 patients ( 75 cases of common peroneal nerve palsy) the common causes were trauma about the knee or about the hip, compression, and underlying neuropathy. A few palsies occurred spontaneously for no apparent reason. The prognosis was uniformly good in the compression group; recovery was delayed but usually satisfactory in patients who had suffered stretch injuries. In the acute stage, when clinical paralysis appears to be complete, electrophysiological studies are a useful guide to prognosis. They may also indicate an underlying neuropathy and they detect early evidence of recovery. The anatomical peculiarities of the common peroneal nerve are noted and aspects of the clinical picture, management, and prognosis of palsy are discussed.

Drop foot caused by common peroneal (lateral popliteal) nerve palsy is a common clinical condition. Large studies of the condition in military casualties are available (Clawson and Seddon, 1960) and are summarised by Sunderland (1968). The trauma is often severe and disruptive with a large number of missile wounds and with associated damage to the sciatic nerve. A recent study of a civilian population (Kline, 1972) described a relatively large number of cases due to gunshot wounds. Other published reports deal with small numbers of patients with palsy due to single causes. Ferguson and Liversedge (1954) described nine cases of ischaemic peroneal palsy. Marwah (1964) and Garland and Moorhouse (1952) considered palsies of a spontaneous and compressive type. White (1968) described traction injuries of the common peroneal nerve and reviewed the earlier reports by Platt (1940) and Highet and Holmes (1943). Reports of more unusual cases are also available. Nobel (1966) described two cases of peroneal nerve palsy due to haematoma within the nerve sheath after severe inversion injury of the ankle. Others have described ganglia of the common peroneal nerve (Brooks, 1952; Parkes, 1961 ; Cobb and Moiel, 1974). Most of the patients in these studies were assessed without the aid of electrophysiological tests.

Hodes et al. (1948) demonstrated the technique of motor nerve conduction velocity measurement in

\footnotetext{
${ }^{1}$ Address for correspondence: St Michael's Hospital, 30 Bond Street, Toronto, Ontario, Canada M5B 1 W8.

(Accepted 27 July 1976.)
}

man, and this was applied to the common peroneal nerve by Thomas et al. (1959). Conduction studies of the common peroneal nerve have been used chiefly for detecting peripheral neuropathy. Behse and Buchthal (1971) described a method of improved localisation of a lesion at the neck of the fibula. Singh et al. (1974) measured sensory and motor conduction velocity over the upper and lower segments of the common peroneal nerve the better to localise the lesion. It seems opportune to describe the clinical features of a relatively large number of patients with palsy due to various causes in whom nerve conduction studies and electromyographical examination have been performed.

METHOD

\section{PATIENTS}

The series is of 75 cases of palsy in 70 patients who were referred for assessment as inpatients or outpatients to the electrophysiological laboratory of a large urban general hospital. Fifty-two were male and 18 were female. Their ages ranged from 15 to 84 years with a median of 45 years. Most patients were assessed within one week to six months of the onset of the palsy and the majority were examined within the first three months. Ten patients were first seen six months after the onset of the drop foot.

Neurological examination for muscle atrophy, weakness, sensory disturbance, and reflex change was undertaken in all patients. Muscle weakness was graded on the MRC scale and the degree of weakness 
of individual muscles innervated by the common peroneal nerve was noted. Peroneus tertius involvement was not specifically assessed.

\section{ELECTROPHYSIOLOGICAL ASSESSMENT}

Measurement of common peroneal nerve motor conduction velocity was attempted in all cases. Bipolar stimulation with a square wave pulse of 0.1 to $0.5 \mathrm{~ms}$ duration and a voltage up to $500 \mathrm{~V}$ was applied to the nerve at the ankle and the neck of the fibula. The response of the extensor digitorum brevis muscle was detected with a surface or a concentric needle electrode. Appropriate muscles were also sampled with concentric needle electrodes to detect surviving motor units, completeness of the interference pattern, and any evidence of denervation of individual muscles.

Conduction measurements of the ipsilateral tibial (medial popliteal) nerve and the opposite common peroneal nerve and sensory and motor conduction studies of the nerves of the upper extremities were also performed when there was reason to suspect a generalised neuropathy. Sensory action potentials in lower limbs were not determined. The degree of electrical severity was graded as follows. Grade Amotor conduction velocity greater than $40 \mathrm{~m} / \mathrm{s}$. Grade B-motor conduction velocity between 30 and $40 \mathrm{~m} / \mathrm{s}$. Grade $\mathrm{C}$-motor conduction velocity less than $30 \mathrm{~m} / \mathrm{s}$ or unobtainable but with preserved motor unit potentials on volition or with estimated supramaximal stimulation. Grade D-no demonstrable conduction; no action potentials under voluntary control or with estimated supramaximal stimulation.

This method of grading was used in patients examined between one week and six months after the onset of the palsy. In patients seen at a later date it was occasionally necessary to adjust the electrical grade to allow for recovery that had occurred. Patients classified in this retrospective manner were not included in the analysis.

\section{FOLLOW-UP}

Assessment was deemed adequate when a patient had been followed up to the point of complete or near complete recovery or when more than one year from the onset had elapsed. Follow-up was adequate in 46 of the 75 palsies. Seventeen patients were too early in the course of the condition, eight were lost to followup, and four died. The degree of recovery was assessed according to the following scale: good = full strength or slight residual weakness, mild numbness; moderate $=$ significant motor and sensory deficit but with useful function; poor $=$ no useful function.

\section{RESULTS}

A summary of the entire series of patients is given in Table 1. The major causes were traumatic or operative injury about the knee, injuries or other conditions affecting the nerve at the level of the hip joint, forced ankle inversion, spontaneous or compressive forms in patients with or without underlying neuropathy, and a few examples of progressive palsy. In several patients in whom more than one possible factor could be implicated classification to a single cause had to be somewhat arbitrary.

Table 2 relates the electrophysiological grading to outcome in 34 patients who were assessed early enough in the course of the paralysis and for whom adequate follow-up information was available. Patients with progressive palsy were excluded. Electrophysiological grading, as defined, is a good indicator of prognosis. In those patients with incomplete paralysis electrophysiological examination is not strictly necessary but it may detect an underlying neuropathy. When paralysis is complete electrical studies may indicate an incomplete lesion with surviving motor units under voluntary control or responsive to nerve stimulation, and we encountered this finding in 10 out of 26 patients. Electrical grading does not indicate the prognosis in the progressive cases. It might have been predicted that cases of peripheral neuropathy and atrophy of the extensor digitorum brevis muscle would be interpreted as being more severe than they proved to be on follow-up, but this was not our experience in this limited series. Similarly, an outcome worse than that indicated by electrophysiological grading might have been predicted in the sciatic nerve cases, but this was not our finding in this relatively small number of patients.

Table 3 shows the major causes and indicates the degree of severity in each group. The severity, and hence the prognosis, varied in the knee trauma group. The palsy was usually severe in the hip trauma group and the prognosis poor. Paralysis in patients with underlying neuropathy tended to be more severe than in the spontaneous and compressive groups. The degree of involvement in the spontaneous and compressive group was relatively mild and the prognosis good. In those patients with purely blunt trauma about the knee (14 patients, 15 palsies)-excluding laceration, Volkmann's ischaemia, penetrating and operative injuries-the prognosis was favourable. The prognosis was poor in the two patients with Volkmann's ischaemia complicating fracture of the tibia and fibula and was also poor in the two patients with traumatic section of the nerve associated with knee injury. Follow-up in the group due to operative trauma was incomplete. 


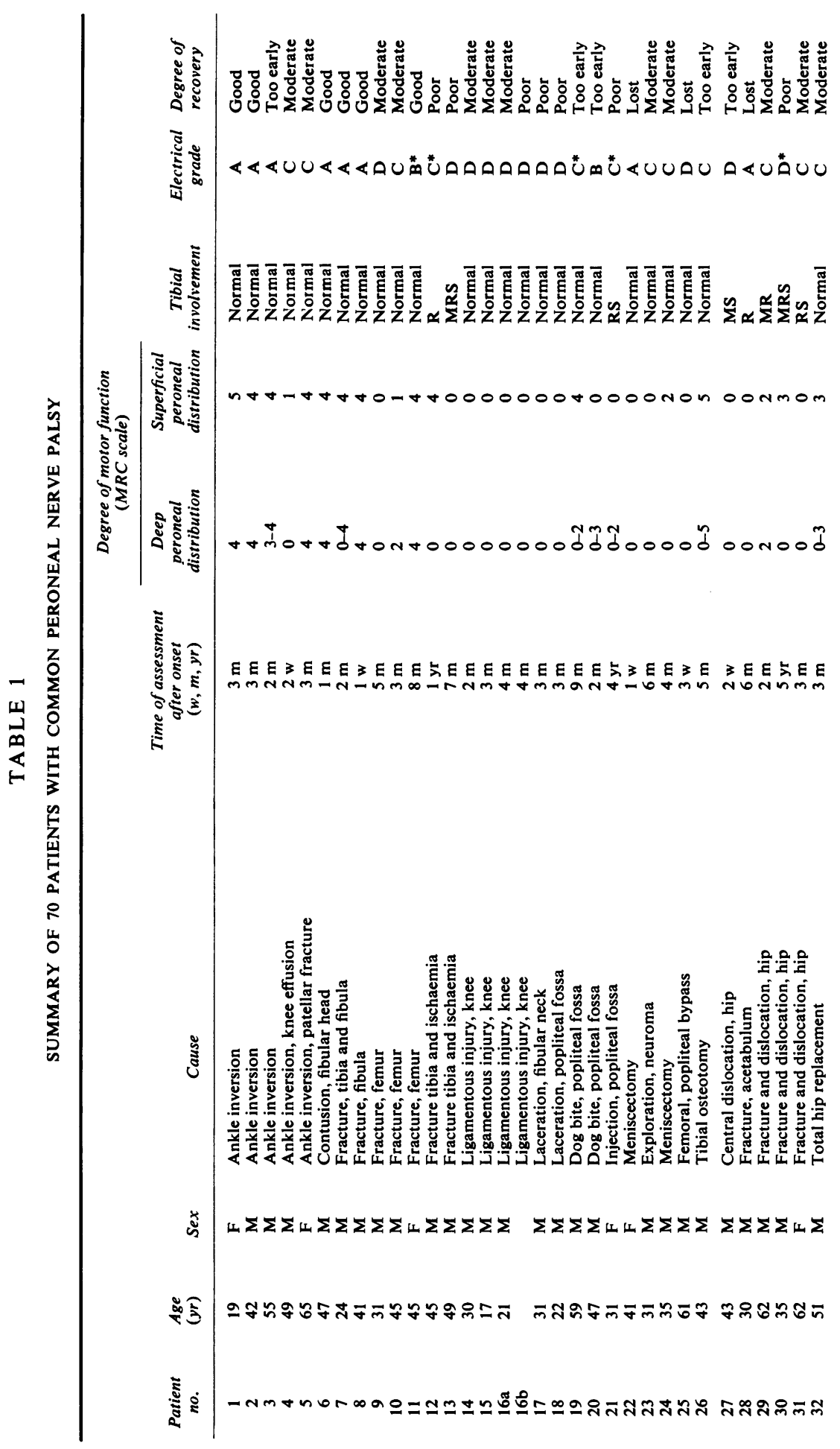




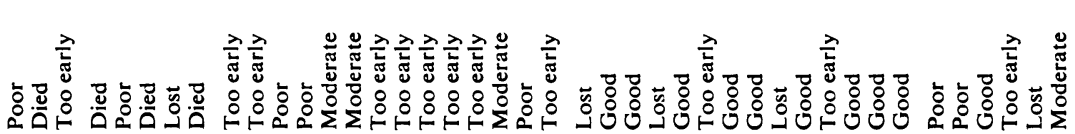

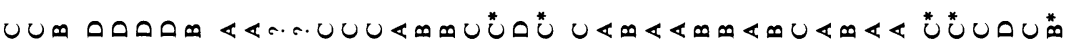

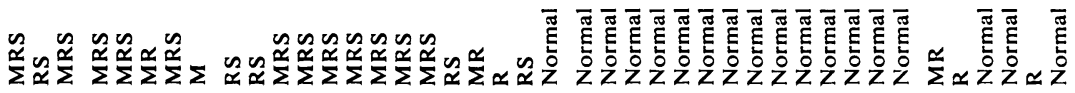

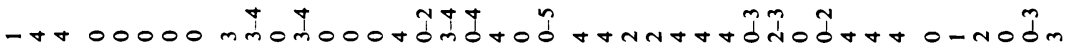

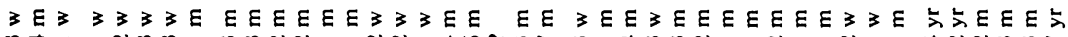
mV- -Nmm- mmNNーーNNーG

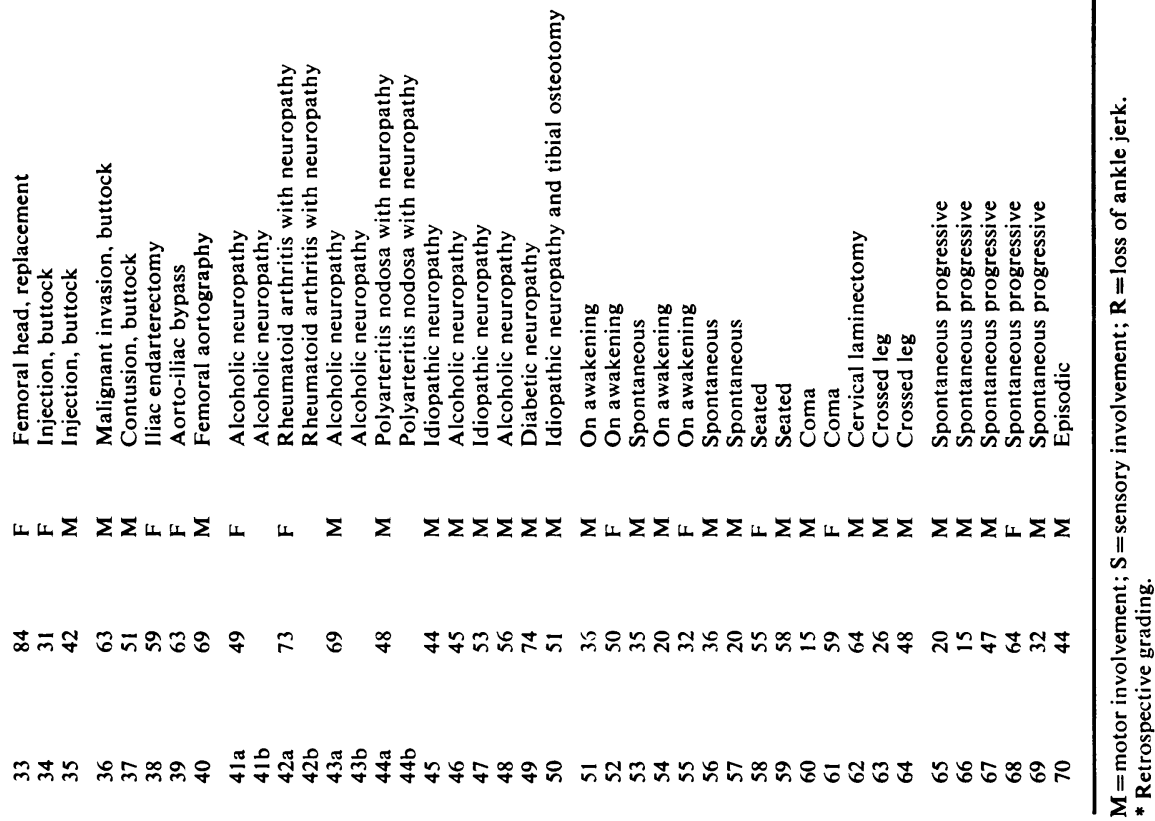


TABLE 2

OUTCOME RELATED TO ELECTROPHYSIOLOGICAL GRADE IN 34 PATIENTS

\begin{tabular}{ccccc}
\hline & \multicolumn{3}{c}{ Recovery } & \\
\cline { 2 - 4 } $\begin{array}{c}\text { Electrical } \\
\text { grade }\end{array}$ & $\begin{array}{c}\text { Good } \\
1\end{array}$ & $\begin{array}{c}\text { Moderate } \\
2\end{array}$ & $\begin{array}{c}\text { Poor } \\
3\end{array}$ & Total \\
\hline A & 10 & & & 10 \\
B & 3 & & & 3 \\
C & 1 & 10 & 1 & 12 \\
D & & 4 & 5 & 9 \\
\hline
\end{tabular}

TABLE 3

CAUSATION RELATED TO SEVERITY IN 75 PALSIES

\begin{tabular}{|c|c|c|c|c|c|}
\hline \multirow[b]{2}{*}{ Cause } & \multicolumn{4}{|c|}{ Electrical grade } & \multirow[b]{2}{*}{ Total } \\
\hline & $A$ & $B$ & $C$ & $D$ & \\
\hline $\begin{array}{l}\text { Trauma } \\
\text { about knee }\end{array}$ & 7 & 2 & 9 & 9 & 27 \\
\hline $\begin{array}{l}\text { Trauma } \\
\text { about hip }\end{array}$ & 1 & 2 & 5 & 6 & 14 \\
\hline Neuropathy & 3 & 2 & 6 & 1 & 14 \\
\hline $\begin{array}{l}\text { Spontaneous } \\
\text { compressive }\end{array}$ & 7 & 5 & 2 & 0 & 14 \\
\hline Progressive & 0 & 1 & 4 & 1 & 6 \\
\hline
\end{tabular}

Table 4 gives a summary of the five patients who had complete paralysis secondary to blunt trauma about the knee, excluding the two patients with Volkmann's ischaemic contracture. The injury seems to be comparable to what White (1968) has described as 'severe stretch injuries'. The knee was repaired in all five patients. The nerve was adequately seen in four patients and was in continuity. Clinical recovery was first noted after eight to 15 months and it continued over a further period of more than one year. Four of the five patients regained useful function, and, in our experience, this type of complete paralysis seems to have a better prognosis than that due to sciatic nerve injury or that associated with Volkmann's ischaemia.

Fourteen patients developed drop foot after hip trauma or after an operation in the region of the hip. Thirteen of them had additional tibial nerve involvement, and there was therefore reason to suspect sciatic nerve injury at the level of the hip or proximal thigh. The degree of paralysis of common peroneal nerve function was complete in eight of the 14 cases. Tibial nerve function was completely absent in three and partial or full in the remainder. In this group of sciatic nerve injury the loss of common peroneal function was always greater than that of tibial nerve function. Persisting pain or troublesome dysaesthesias were a feature in more than half of the patients with features of sciatic nerve injury, whereas it was found in less than one quarter of the patients in the groups due to other causes.

In 10 patients a generalised peripheral neuropathy was diagnosed from nerve conduction studies, and eight of them had obvious clinical features of neuropathy. Alcoholism was present in four, vasculitis associated with collagen disease in two, and diabetes in one. The neuropathy was idiopathic in three patients. In four patients the palsy was bilateral. The palsy in the neuropathy group tended to be more severe than in the spontaneous or compressive group and the outcome was correspondingly poorer. Mulder et al. (1961) demonstrated an increased susceptibility to pressure palsy in diabetic neuropathy, and this is also seen in neuropathy due to alcoholism and other causes.

Fourteen patients (nos. 51 to 64) could be classified in the spontaneous or compressive group. In fivepatients there was a history indicative of compression -operative or postoperative, during coma, or during $\frac{9}{\mathbb{Q}} \mathrm{O}$ leg crossing. In six others compression was the likely ․ cause since the palsy was noted on wakening or aftero sitting for a long period of time. In three patients 8 compression could not be invoked and the onset wase spontaneous with further progression over a day or two. The prognosis was uniformly excellent in this group of 14 patients, as has also been described by Garland and Moorhouse (1952). There was no clinical evidence of peripheral neuropathy in these patients, although sensory and motor conduction studies in the upper extremities were not performed in all. It is of interest that pain was present at the onset in four patients, in contrast with the experience of Garland and Moorhouse (1952), who reported an absence of pain in a study of 20 patients.

Table 5 gives the details in five patients with progressive palsy. Progression occurred over weeks to months, often with pain, and the weakness was usually severe by the time of our examination. Three patients underwent surgical exploration and a definite entrapment was encountered in only one patient. One patient improved and two failed to improve after exploration. The severity of the palsy and its duration may have accounted for the lack of improvement, although no definite abnormality was seen at exploration. One patient was not explored although there was a palpable thickening of the nerve at the neck of the fibula.

Table 6 gives details of the remaining patients who underwent operation. Six patients in the injury and 
TABLE 4

TRAUMA ABOUT THE KNEE WITH COMPLETE PARALYSIS IN 5 PATIENTS

\begin{tabular}{|c|c|c|c|c|c|c|c|}
\hline \multirow[b]{2}{*}{$\begin{array}{l}\text { Patient } \\
\text { no. }\end{array}$} & \multirow[b]{2}{*}{$\begin{array}{l}\text { Structures } \\
\text { involved }\end{array}$} & \multirow[b]{2}{*}{$\begin{array}{l}\text { Appearance of nerve } \\
\text { at operation }\end{array}$} & \multirow{2}{*}{$\begin{array}{l}\text { First evidence } \\
\text { of recovery } \\
\text { (months) }\end{array}$} & \multirow[b]{2}{*}{$\begin{array}{l}\text { Length of } \\
\text { follow-up }\end{array}$} & \multicolumn{3}{|c|}{ Degree of recovery } \\
\hline & & & & & $\begin{array}{c}\text { Individual } \\
\text { muscle }(M R C)\end{array}$ & Sensory & Overall \\
\hline 1 & $\begin{array}{l}\text { Knee capsule } \\
\text { Cruciate ligament } \\
\text { Lateral ligament }\end{array}$ & Damage over $6 \mathrm{~cm}$ & 15 & $3 \frac{1}{2} \mathrm{yr}$ & $\begin{array}{l}\text { Tib. ant. } 4 \\
\text { Peronei } 4 \\
\text { Others } 0\end{array}$ & Numbness & Moderate \\
\hline 2 & $\begin{array}{l}\text { Cruciate ligament } \\
\text { Lateral ligament } \\
\text { Biceps tendon }\end{array}$ & 'Adhesions' & 11 & $5 \mathrm{yr}$ & $\begin{array}{l}\text { Tib. ant. } 4 \\
\text { EHL } 4 \\
\text { Evertors } 4\end{array}$ & No deficit & Moderate \\
\hline 3 & $\begin{array}{l}\text { Cruciate ligament } \\
\text { Knee capsule } \\
\text { Popliteal }\end{array}$ & Not seen & 13 & $15 \mathrm{~m}$ & $\begin{array}{l}\text { Tib. ant. } 3 \\
\text { EDL } 3 \\
\text { Peronei } 4 \\
\text { EHL \& EDB }\end{array}$ & $\begin{array}{l}\text { No deficit } \\
0\end{array}$ & Moderate \\
\hline 4 & $\begin{array}{l}\text { Cruciate ligament } \\
\text { Lateral ligament } \\
\text { Biceps tendon }\end{array}$ & $\begin{array}{l}\text { Attenuation over } \\
\text { long distance }\end{array}$ & & $15 \mathrm{~m}$ & $\begin{array}{l}\text { All } 0 \\
\text { (Few motor } \\
\text { units in } \\
\text { Tib. ant.) }\end{array}$ & No deficit & Poor \\
\hline 5 & Fractured femur & $\begin{array}{l}\text { Contusion at head } \\
\text { of fibula }\end{array}$ & 8 & $15 \mathrm{~m}$ & All 4 & $\begin{array}{l}\text { Slight } \\
\text { numbness }\end{array}$ & Moderate \\
\hline
\end{tabular}

TABLE 5

DETAILS OF PROGRESSIVE PALSIES IN 5 PATIENTS

\begin{tabular}{|c|c|c|c|c|c|}
\hline Cause & $\begin{array}{l}\text { No. of } \\
\text { cases }\end{array}$ & $\begin{array}{l}\text { Length of } \\
\text { progression }\end{array}$ & Other features & $\begin{array}{l}\text { Electrical } \\
\text { grade }\end{array}$ & Management and outcome \\
\hline Entrapment & 1 & $2 \mathrm{~m}$ & Pain & C & $\begin{array}{l}\text { Improvement after release of } \\
\text { entrapment }\end{array}$ \\
\hline Idiopathic & 3 & $6 w-3 m$ & $\begin{array}{l}\text { One with pain. } \\
\text { All with absent } \\
\text { ankle jerks }\end{array}$ & $\mathrm{C}, \mathrm{C}, \mathrm{D}$ & $\begin{array}{l}\text { Exploration in } 2 \text {; no definite } \\
\text { entrapment; no improvement }\end{array}$ \\
\hline $\begin{array}{l}\text { Palpable cylindrical } \\
\text { thickening of nerve } \\
\text { at fibula }\end{array}$ & 1 & $3 w$ & & $\mathbf{D}$ & Not explored; no improvement \\
\hline
\end{tabular}

TABLE 6

DETAILS OF 15 PATIENTS SURGICALLY EXPLORED

\begin{tabular}{|c|c|c|c|c|c|}
\hline Time after onset & Reason for operation & $\begin{array}{l}\text { No. of } \\
\text { cases }\end{array}$ & $\begin{array}{l}\text { Electrical } \\
\text { grade }\end{array}$ & Findings at operation & Recovery \\
\hline \multirow{3}{*}{$\begin{array}{l}\text { Early or } \\
\text { intermediate } \\
\text { ( } 4 \text { days to } 2 \text { months) }\end{array}$} & $\begin{array}{l}\text { Repair of knee; nerve also } \\
\text { examined }\end{array}$ & 3 & $\mathbf{D}$ & Continuity & Slow improvement \\
\hline & Suspected section of nerve & 2 & $\mathbf{D}$ & $\begin{array}{l}1 \text { complete section } \\
1 \text { partial section }\end{array}$ & No improvement \\
\hline & Post-meniscectomy palsy & 1 & $\mathbf{A}$ & Continuity & Not known \\
\hline \multirow[t]{4}{*}{$\begin{array}{l}\text { Late } \\
\text { (after } 2 \text { months) }\end{array}$} & Suspected entrapment & 5 & $\underset{\text { D }}{\mathrm{B}, \mathrm{C}, \mathrm{C}, \mathrm{C}}$ & 1 entrapment & Improvement \\
\hline & & & & $\begin{array}{l}4 \text { no definite } \\
\text { entrapment }\end{array}$ & No improvement \\
\hline & $\begin{array}{l}\text { Traumatic palsy with failure } \\
\text { to improve }\end{array}$ & 3 & $\mathbf{B}, \mathbf{D}, \mathbf{D}$ & $\begin{array}{l}\text { In continuity with } \\
\text { electrical activity }\end{array}$ & $\begin{array}{l}\text { Slow improvement in } 2 \text {, } \\
\text { no improvement in } 1\end{array}$ \\
\hline & Painful post-traumatic neuroma & 1 & & Neuroma & $\begin{array}{l}\text { Relief of pain, gradual } \\
\text { improvement }\end{array}$ \\
\hline
\end{tabular}


trauma group were explored at the onset or early in the course of the paralysis. In three the nerve was inspected during knee repair and was found to be in continuity in spite of a complete paralysis by clinical and electrophysiological criteria. Two patients with skin lacerations and complete paralysis required exploration to assess continuity and for nerve suture when necessary. One patient was explored unnecessarily, one week after the onset of paralysis after a meniscus removal; electrophysiological tests showed an incomplete palsy with preserved conduction. Exploration was undertaken late in the course of the condition because of failure to improve, progression of the paralysis, and, in two instances, continuing pain. These features led to a suspicion of entrapment, although this was verified in only one patient.

Delay in onset of the paralysis was a definite feature in 11 of the 27 patients who had suffered either blunt, penetrating, or operative trauma about the knee. In four of these patients the apparent delay may have been due to the application of plaster, traction, or Volkmann's ischaemia, but in seven there was no identifiable cause. Furthermore, delayed onset was commoner in patients who had suffered blunt trauma about the knee. The mechanism of the delay is obscure but it could be due to compression of the nerve by haemorrhage or oedema.

In most patients individual muscles were involved to an equal degree. In 21 there was some disparity and this was notable from the onset; in the remainder it was noted during recovery. The commonest pattern of disparity was that of preservation of peroneal muscle function with little or no function of the muscles of the anterior tibial compartment. Occasionally the converse was encountered. Five patients with severe paralysis of the extensor hallucis muscle were seen, and in three it was noted in the recovery phase. In the remaining two patients the paralysis developed after tibial osteotomy and a nerve lesion of the branch to the extensor hallucis longus muscle was suspected. In four of these patients with selective loss of extensor hallucis function the extensor digitorum brevis muscle was also completely affected. Sunderland (1968) has noted that the fibres which supply the extensor hallucis longus and extensor digitorum brevis muscles, as well as some of the fibres of the extensor digitorum longus muscle, lie close together as the nerve crosses the fibula and may therefore be vulnerable to injury.

\section{DISCUSSION}

\section{DIFFERENTIAL DIAGNOSIS}

The most usual cause of unilateral drop foot is common peroneal nerve palsy of a spontaneous, traumatic, or pressure type. The progressive variety or that due to vasculitis are much less common. Drop foot is occasionally caused by lumbar intervertebral disc disease with herniation and compression of the L5 root; the pattern of muscle involvement within the common peroneal nerve territory is identical although the degree of muscular paralysis is always incomplete. The sensory disturbance is similar. There is weakness of the tibialis posterior muscle, and this is a useful point of distinction; in addition there may be weakness of the hamstring muscles. Back pain, sciatica, and limitation of straight leg raising are evident and the two conditions are usually easy to distinguish. Motor conduction velocity remains normal with L5 root compression, although evidence of denervation may be encountered in the appropriate muscles.

Rarely, intervertebral disc disease with multiple root involvement (L5 and S1) may produce a similar picture. We encountered two such cases. There was evidence of muscle involvement in a wider segmental territory and the condition was readily distinguished from that of common peroneal nerve palsy. We have not seen some of the more unusual causes of single nerve root disturbance such as schwannomas or $\vec{N}$ spondylolisthesis.

Motor neurone disease often begins in the lowero요 extremities, and when the onset is asymmetrical ito may present as a drop foot. The clinical features of lower motor neurone type weakness-fasciculationo 0 and absence of sensory disturbance, with upper motor neurone manifestations-should allow of ano easy distinction. Motor conduction is normal until late in the condition and over the next months there iso involvement of additional muscles and of the opposite extremity. In general, it can be said that these conditions are distinguishable and the diagnosis of common peroneal nerve palsy can be established clearly on clinical grounds in almost every patient.

When the drop foot is bilateral a different order of causes must be considered. Evidence of involvement of other nerves is almost invariably present as in the generalised neuropathy of an idiopathic type, in alcoholism, collagen disease, or Charcot-MarieTooth disease. Our eight patients with CharcotMarie-Tooth disease all showed prolonged motor conduction in the upper limbs. We have seen patients with cauda equina disturbance due to intervertebral disc disease and arachnoiditis with bilateral foot drop but with widespread involvement of the muscles of the thighs and pelvic girdle. Distinction from common peroneal nerve palsy has not been a problem.

\section{ANATOMICAL CONSIDERATIONS}

Sunderland (1968) states that the fascicles which make up the tibial and common peroneal nerve remain separate throughout the length of the sciatic 
nerve, although they are enveloped in a common epineurium. Two distinct nerves normally emerge at the upper border of the popliteal fossa. The common peroneal nerve passes downward and inferolaterally under cover of the biceps tendon and is separated from the lateral femoral condyle by the upper portion of the gastrocnemius and plantaris muscles. It continues posterior to the tendon of the popliteus muscle and to the tendinous attachment of the soleus to the fibular head. The common peroneal nerve now curves around the neck of the fibula, and our dissection studies show that it is applied to the periosteum of the fibula for a total of about $10 \mathrm{~cm}$. The nerve passes through a tunnel, the roof of which is formed by the origin of the peroneus longus muscle and the intermuscular septum. The upper portion of the arch of the tunnel is attached to the head of the fibula and the lower portion of the arch to the lateral aspect of the upper portion of the shaft of the fibula. Kopell and Thompson (1963) note that the fibromuscular opening of the tunnel may have a J-shaped outline and that the curved portion of the $J$ forms the inferior margin of the opening.

The common peroneal nerve usually divides into three branches - the articular branch to the capsule of the knee; the deep peroneal nerve (anterior tibial nerve), which passes through a second fibro-osseous canal formed by the origin of the extensor digitorum longus muscle about $4 \mathrm{~cm}$ below the first tunnel and which supplies muscles of the anterior compartment and the third branch; and the superficial peroneal (musculocutaneous) nerve which runs deep to and between the peroneal muscles and supplies the peroneus longus, brevis, and the skin. In one half of the cases there is a muscular branch to one of the muscles in either the anterior or lateral compartments before the regular division of the nerve into its three branches (Sunderland, 1968). The major branches also vary. In 20 patients analysed by Sunderland the division into the three branches occurred proximal to the tunnel in two, at or within the tunnel in seven, and up to $3.9 \mathrm{~cm}$ below the tunnel in 11 .

Several peculiarities of the common peroneal nerve make it vulnerable to injury. It is exposed over a bony prominence for about $4 \mathrm{~cm}$ covered only by skin and superficial fascia and is susceptible to direct blows and lacerations. It is readily compressed at that site when the patient sits with legs crossed or when consciousness is diminished and it is endangered in fractures. Nobel (1966) has noted limited longitudinal mobility of the nerve and our dissection studies show that the passage of the common and deep peroneal nerves through the two tunnels limits mobility in a longitudinal direction to about $0.5 \mathrm{~cm}$. The large number of branches which arise immediately below the knee contribute to this fixation. The epineurium is not usually adherent to the superficial fascia or periosteum but adhesions may occur as a result of injury, and we saw this at the time of exploration in several of our patients. It can thus be seen that longitudinal stretch forces applied to the nerve in injuries such as forced ankle inversion or in proximal injuries such as posterior hip dislocation can result in a stretch injury of the common peroneal nerve. Several examples are included in this series. The relative thickness of the epineurium - that is, the ratio of epineurium to fascicular area on cross section-influences the susceptibility to stretch injuries (Haftek, 1970). The ratio is greatest with respect to the sciatic nerve in the gluteal region and is least with respect to the common peroneal nerve (Sunderland, 1968). The presence of the fibro-osseous tunnel creates an opportunity for entrapment analogous to that seen in carpal tunnel syndrome, but this appears to be a relatively rare factor in causation with respect to the common peroneal nerve.

Passage through the fibro-osseous tunnel can lead to interference if any of the structures should be involved in swelling or haemorrhage; this may be the basis of the delayed type of palsy seen in our patients who suffered blunt trauma about the knee. Nobel (1966) operated on two patients who developed painful common peroneal nerve palsy after torsional injuries about the knee and found haematoma within the nerve sheath at the level of the popliteal fossa. Swelling and haemorrhage within the anterior tibial compartment due to local trauma may result in a painful partial peroneal nerve palsy (Rorabeck et al., 1972). It might be argued that some of our delayed cases were due to this type of haematoma within the nerve sheath, except that pain was not a feature.

\section{ELECTROPHYSIOLOGICAL ASSESSMENT}

Electrical studies are usually superfluous to the diagnosis of drop foot but they are of value in assessing prognosis and in detecting early signs of recovery. Prolonged motor conduction of other nerves may indicate an underlying neuropathy. It is adequate to sample muscles within the anterior and lateral compartments and to obtain conduction values from the neck of the fibula to the extensor digitorum brevis muscle. When this muscle is totally atrophic or inaccessible conduction velocity cannot be measured but latency values to individual muscles can be determined (Redford, 1964). Our experience with this has been too limited to allow of any useful comment. The technique of nerve stimulation at consecutive points, as described by Carpendale (1966), could be applied to the common peroneal nerve in order to define the site of the lesion, and the technique of sciatic nerve conduction (Gassel and 
Trojaborg, 1964) could be used to detect lesions within the thigh. We have not had any experience with these techniques nor with that of Behse and Buchthal (1971). In the patients with complete paralysis we found the earliest evidence of recovery to occur within the upper portion of the tibialis anterior muscle or the peronei; nascent motor unit potentials should be looked for, and these were first detected two to eight months after the onset of the palsy.

The lateral half of the extensor digitorum brevis muscle may be innervated by a branch of the superficial peroneal nerve (musculocutaneous nerve) and Lambert (1969), by means of nerve stimulation, found this in $22 \%$ of limbs. Gutmann (1970) described two patients with lesions of the deep peroneal nerve (anterior tibial nerve) due to fibular chondroma and a ganglion cyst, in which a portion of the extensor digitorum brevis muscle was preserved, with normal motor conduction velocity of the common peroneal nerve. The practical importance of this 'accessory deep peroneal nerve' is not great since the site of most lesions is situated at or proximal to the neck of the fibula and is above the origin of the accessory branch. We did not experience any misleading observations due to this anatomical variant.

\section{MANAGEMENT}

When the palsy is incomplete, with slight to moderate weakness, the prognosis is uniformly good and the patient may be reassured of this. If the drop foot develops after diminished consciousness due to head injury, anaesthesia, or other cause there is no clear indication for any further medical or electrophysiological investigation and such patients usually recover in a few weeks. When the condition develops spontaneously in an otherwise healthy patient an inquiry into general health, alcoholism, or diabetes is relevant. Here nerve conduction studies may show reduced velocity in other nerves and indicate a generalised neuropathy. This should lead to appropriate medical investigation.

Progressive cases do require investigation. Underlying neuropathy should be looked for, although we did not find any examples of it. Electrical tests serve to confirm the progression, and if the cause is not apparent it is reasonable to recommend surgical exploration.

Total paralysis, apart from the occasional patient with underlying generalised neuropathy or a progressive palsy, is, in our experience, always on the basis of trauma. In blunt injuries about the knee severance of the nerve is unlikely and is also unlikely in most patients with dislocations of the hip or knee or fractures of the femur, tibia, fibula, or ankle injuries. If the lesion is incomplete clinically there is no definite need for electrical testing and recovery can be followed by clinical observation alone. In those patients where the lesion appears to be complete electrical testing and a more careful follow-up is required. Electromyographic evidence of recovery should be looked for. In our experience this occurred within two to 15 months. When the continuity of the nerve is in doubt it is probably unreasonable to wait for evidence of recovery beyond six months. Exploration was thus performed in three of our patients three months, six months, and one year after injury and continuity was found in all. As in our study a number of patients will already have undergone exploration at the time of surgical repair to the knee. Observations made at that time as to the appearance of the nervebruising, attenuation, and length of the injured segment-indicate the severity of the injury and help to indicate whether the recovery will be delayed or incomplete. It should be noted that all patients in our series in the group who suffered blunt trauma about the knee had a nerve in continuity at the time of surgical repair of the knee.

Reports have given a poor prognosis for stretchen $\vec{N}$ injuries, and the role of surgical intervention in these $\overrightarrow{-}$ patients deserves some comment. Platt (1940) des $\overrightarrow{\mathbb{D}} \overrightarrow{\mathrm{N}}$ cribed nine cases, four of which had complete rupture of the nerves at operation. In the remaining casesi where the nerve was in continuity exploration hado 0 been undertaken within the first seven weeks, and the author concluded that the injured nerve should be요 explored within the first few weeks of the accident We would say that this is too early to allow of the detection of recovery. Highet and Holmes $(1943) \vec{\varphi}$ operated on eight patients with traction injury from $\sigma$ four to 11 months after the accident. In six of these patients resection and suture were carried out. Only one patient made any recovery. White (1968) described a better outlook. Six traction injuries of the common peroneal nerve were documented in association with severe adduction forces to the knee. In two there was disruption of the nerve and suture was performed with good results. In the other four the nerve was in continuity and all made a good recovery. This author recommended exploration at three months if there was no evidence of recovery. Our experience justifies a more optimistic note; four out of five patients experienced a return of useful function. We would defer surgical exploration for about six months and wait for evidence of recovery unless there was an additional reason to suspect discontinuity of the nerve.

In cases of a penetrating or lacerating injury or of extensive bony injury, severance of the nerve should be suspected. If nerve conduction is absent with no surviving motor units surgical exploration is needed. There were two such patients in our study, and the 
operative findings were complete transection of the nerve in one and partial in the other. In such patients surgical repair should be undertaken and end-to-end suture is usually possible (Kline, 1972). In the experience of Seddon (1972) one-third of such patients had a useful recovery.

Of all the patients with complete paralysis (group D) about half experienced a useful degree of recovery and the outcome was slightly better in the blunt knee trauma group. A permanent drop foot brace may be required in patients who do not recover and the usual remedial surgical treatment is that of tendon transfer.

\section{REFERENCES}

Behse, F., and Buchthal, F. (1971). Normal sensory conduction in the nerves of the leg in man. Journal of Neurology, Neurosurgery, and Psychiatry, 34, 404-414.

Brooks, D. M. (1952). Nerve compression by simple ganglia. Journal of Bone and Joint Surgery, 34B, 391-400.

Carpendale, M. T. (1966). The localization of ulnar nerve compression in the hand and arm: an improved method of electroneuromyography. Archives of Physical Medicine and Rehabilitation, 47, 325-330.

Clawson, D. K., and Seddon, H. J. (1960). The late consequences of sciatic nerve injury. Journal of Bone and Joint Surgery, 42B, 213-225.

Cobb, C. A., and Moiel, R. H. (1974). Ganglion of the peroneal nerve. Journal of Neurosurgery, 41, 255-259.

Ferguson, F. R., and Liversedge, L. A. (1954). Ischaemic lateral popliteal nerve palsy. British Medical Journal, 2, 333-335.

Garland, H., and Moorhouse, D. (1952). Compressive lesions of the external popliteal (common peroneal) nerve. British Medical Journal, 2, 1373-1378.

Gassel, M. M., and Trojaborg, W. (1964). Clinical and electrophysiological study of conduction times in the distribution of the sciatic nerve. Journal of Neurology, Neurosurgery, and Psychiatry, 27, 351-456.

Gutmann, L. (1970). Atypical deep peroneal neuropathy. Journal of Neurology, Neurosurgery, and Psychiatry, 33, 453-456.

Haftek, J. (1970). Stretch injury of peripheral nerve. Journal of Bone and Joint Surgery, 52B, 354-365.

Highet, W. B., and Holmes, W. (1943). Traction injuries to the lateral popliteal nerve and traction injuries to peripheral nerves after suture. British Journal of Surgery, 30, 212-233.

Hodes, R., Larrabee, M. G., and German, W. (1948). The human electromyogram in response to nerve stimula- tion and the conduction velocity of motor axons. Archives of Neurology and Psychiatry (Chic.), 60, 340-365.

Kline, D. G. (1972). Operative management of major nerve lesions of the lower extremity. Surgical Clinics of North America, 52, 1247-1265.

Kopell, H. P., and Thompson, W. A. L. (1963). Peripheral Entrapment Neuropathies. Williams and Wilkins: Baltimore.

Lambert, E. H. (1969). The accessory deep peroneal nerve. Neurology (Minneap.), 19, 1169-1176.

Marwah, V. (1964). Compression of the lateral popliteal (common peroneal) nerve. Lancet, 2, 1367-1369.

Mulder, D. W., Lambert, E. H., Bastron, J., and Sprague, R. G. (1961). The neuropathies associated with diabetes mellitus. A clinical and electromyographic study of 103 unselected diabetic patients. Neurology, (Minneap.), 11, 275-284.

Nobel, W. (1966). Peroneal palsy due to hematoma in the common peroneal nerve sheath after distal torsional fractures and inversion ankle sprains. Journal of Bone and Joint Surgery, 48A, 1484-1495.

Parkes, A. (1961). Intraneural ganglion of the lateral popliteal nerve. Journal of Bone and Joint Surgery, 43B, 784-790.

Platt, H. (1940). Traction lesions of the external popliteal nerve. Lancet, 2, 612-614.

Redford, J. B. (1964). Nerve conduction in motor fibers to the anterior tibial muscle in peroneal palsy. Archives of Physical Medicine and Rehabilitation, 45, 500-504.

Rorabeck, C. H., Macnab, I., and Waddell, J. P. (1972). Anterior tibial compartment syndrome: a clinical and experimental review. Canadian Journal of Surgery, 15, 249-256.

Seddon, H. J. (1972). Surgical Disorders of the Peripheral Nerves. Churchill Livingstone: Edinburgh.

Singh, N., Behse, F., and Buchthal, F. (1974). Electrophysiological study of peroneal palsy. Journal of Neurology, Neurosurgery, and Psychiatry, 37, 1202-12.13.

Sunderland, S. (1968). Nerve and Nerve Injuries. Williams and Williams: Baltimore.

Thomas, P. K., Sears, T. A., and Gilliatt, R. W. (1959). The range of conduction velocity in normal motor nerve fibres to the small muscles of the hand and foot. Journal of Neurology, Neurosurgery, and Psychiatry, 22, 175-181.

White, J. (1968). The results of traction injuries to the common peroneal nerve. Journal of Bone and Joint Surgery, 50B, 346-350. 